Qualitative study-other

\section{After the Liverpool Care Pathway clear guidance and support on end-of-life care is needed}

$10.1136 /$ eb-2015-102170

\section{Peter 0’Halloran}

School of Nursing and Midwifery, Queen's University Belfast, Medical Biology Centre, Belfast, UK

Correspondence to: Dr Peter 0'Halloran, School of Nursing and Midwifery, Queen's University Belfast, Medical Biology Centre, 97 Lisburn Road, Belfast BT9 7BL, UK; p.ohalloran@qub.ac.uk

Commentary on: Ramasamy Venkatasalu $M$, Whiting $D$, Cairnduff K. Life after the Liverpool Care Pathway (LCP): a qualitative study of critical care practitioners delivering end-of-life care. J Adv Nurs 2015;71:2108-18.

\section{Implications for practice and research}

- Experienced practitioners can deliver high-quality end-of-life care without the Liverpool Care Pathway (LCP) but junior nursing and medical staff need clear guidance and support. Evidence-based guidance on family involvement is needed to avoid future controversies.

- Research is needed into how managers and practitioners can address the organisational, professional and cultural factors that undermined the implementation of the LCP and are likely to hinder high-quality end-of-life care in the future.

\section{Context}

For the first 10 years of this century the LCP for the dying patient (a clinical tool developed to improve care for patients in the last days and hours of life) enjoyed wide endorsement from statutory and professional bodies in the UK and internationally, and was used throughout the National Health Service (NHS). Then, in response to reports from patients, relatives and some clinicians, together with often sensationalist reports in sections of the media, the LCP fell into disrepute. Following a negative independent report to the Department of Health in the UK ${ }^{1}$ the LCP was phased out in 2014, to be replaced by five 'Priorities for Care of the Dying Person'. ${ }^{2}$ Ramasamy Venkatasalu et al aimed to explore the experiences, challenges and practices of critical care practitioners after the LCP.

\section{Methods}

A broad qualitative approach was adopted, with data from semistructured interviews with 14 critical care practitioners subject to 'Framework Analysis.' This is acceptable but reference to the specific paradigm espoused by the authors would alert readers to the assumptions underpinning the analysis. It would also be helpful to know how the interview schedule was developed. Overall, the study appears to have been rigorously conducted. Descriptions of researcher characteristics, the context for data collection, sampling and saturation, data collection, participants, data analysis and techniques to enhance rigour are sufficient to inspire confidence in the reader. ${ }^{3}$

\section{Findings}

Stopping the LCP led to a variety of uncertainties and inconsistencies in the delivery of end-of-life care, especially for less-experienced practitioners. The LCP had been useful to structure clinical care but it often led to less individualised care and reduced involvement of the family. Nevertheless, practitioners reported that they still used some of the approaches and practices learned from using the LCP to improve end-of-life-care.

\section{Commentary}

The study is timely and methodologically sound. However, the findings and the implications for practice could be presented in a more nuanced way. What stands out from the data as reported is that the LCP was associated with helpful (structured, logical, consistent care; mutual goal setting and communicating with the family) as well as unhelpful (depersonalised care; lack of family involvement) practices. Similarly, stopping the LCP had beneficial (reduced paperwork) and deleterious (de-skilling of junior critical care staff; inconsistency in care; uncertainty for patients and relatives) effects. This mix of good and bad consequences is acknowledged in the conclusions but not fully discussed. Interestingly, the authors see greater involvement of specialist palliative care services post-LCP negatively as 'over-reliance', when this could also be seen as a positive development.

The authors recommend that future end-of-life care planning approaches should ensure patient and family involvement; that guidance should be issued around key palliative care decisions; and that education and mentorship should be available to critical care practitioners. It would be hard to disagree with these proposals but they may not be enough to produce the desired changes. After all, the LCP documentation and surrounding processes were designed to provide for all these, ${ }^{4}$ so it seems unlikely that the problems experienced stem principally from the nature of the pathway itself. In fact, the evidence is that the NHS has struggled to provide high-quality end-of-life care before, during and after the implementation of the $\mathrm{LCP}^{2}{ }^{5}$-a reality reflected in this paper. Present herculean efforts to improve on the LCP are unlikely to succeed as hoped without attention to hindering cultural, professional and organisational issues that are endemic to the NHS. ${ }^{6}$

\section{Twitter Follow Peter 0’Halloran at @0HallPete}

Competing interests None declared.
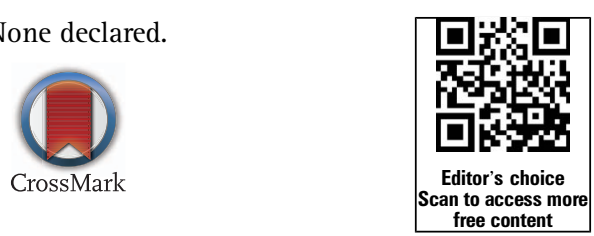

\section{References}

1. DOH. More Care Less Pathway: A Review of the Liverpool Care Pathway. 2013. https://www.gov.uk/government/uploads/system/uploads/attachment_data/file/ 212450/Liverpool_Care_Pathway.pdf

2. DOH. One chance to get it right: one year on report. London, 2015. file://Q:/ Staffhome1/2048388/Publication/EBNcommentary2015/One_chance_-_one_year_ on_acc.pdf

3. O'Brien BC, Harris IB, Beckman TJ, et al. Standards for reporting qualitative research. Acad Med 2014;89:1-7.

4. Ellershaw J. Care of the dying: what a difference an LCP makes! Palliat Med 2007;21:365-8.

5. Al-Qurainy R, Collis E, Feuer D. Dying in an acute hospital setting: the challenges and solutions. Int J Clin Pract 2009;63:508-15.

6. McConnell T, O'Halloran P, Donnelly M, et al. Factors affecting the successful implementation and sustainability of the Liverpool Care Pathway for dying patients: a realist evaluation. BMJ Support Palliat Care 2015;5:70-7. 